\title{
CRAYFISH FEEDING RESPONSES TO ZEBRA MUSSELS DEPEND ON MICROORGANISMS AND LEARNING
}

\author{
BRIAN A. HAZLETT \\ Department of Biology \\ University of Michigan \\ Ann Arbor, Michigan 48109-1048
}

(Received March 18, 1994; accepted May 26, 1994)

\begin{abstract}
Three species of crayfish (Orconectes virilis, 0 . nusticus, and Cambarus robustus) were tested for feeding responses to potential food odors from mollusks (either zebra mussels, Dreissena polymorpha, or native gastropods). In all three crayfish species, feeding responses to odor cues were shown only by individuals experienced with feeding on a prey type. Individuals exposed to just the smell of prey organisms did not show feeding responses, indicating the role of associative leaming in diet breadth. Establishment of a leamed association took more than one feeding experience but once established lasted more than three weeks. When microbial enzymatic degradation of food protein was eliminated, either by UV radiation or microfiltration, feeding responses were eliminated even for crayfish experienced with a prey type.
\end{abstract}

Key Words-Feeding, leaming, microorganisms, crayfish, Orconectes virilis, Dreissena polymorpha.

\section{INTRODUCTION}

It is widely acknowledged that animals can learn characteristics of items in their diet and that diet breadth is often experience-dependent (Croll and Chase, 1980; Connaughton and Epifanio, 1993; Derby and Atema, 1981; Waldbauer and Friedman, 1968; Wood, 1968). However, the role of learning in the recognition of food by invertebrates is less frequently acknowledged. In addition, although the role of bacteria in ecosystems is well known, the role of bacteria or other agents of degradation in producing food-related cues has been studied in only a few cases (Ikeshoji, 1984; Vissen, 1986). Furthermore, no study has shown that learned responses to food odors are dependent on microorganisms. 
Crayfish are the dominant invertebrates in many freshwater ecosystems (Flint and Goldman, 1975; Momot et al., 1978). They are polytrophic (Hobbs, 1993), feeding predominantly on algal and detrital material scraped from surfaces, but show strong feeding responses to amino acids emanating from animal protein (Tiemey and Atema, 1988). It has been suggested that the feeding activity of crayfish can have very strong effects on both whole communities (Chambers et al., 1990) as well as on particular species, such as zebra mussels, Dreissena polymorpha (Ludyanskiy et al., 1993).

The native crayfish Orconectes virilis has been reported to feed upon $D$. polymorpha in the laboratory (Love and Savino, 1993). Thus initial observations of the lack of response to either intact zebra mussels or the odor of crushed zebra mussels by $O$. virilis that had no experience with that species of mollusk suggested that learning could influence feeding behavior in crayfish. The following experiments were designed to test the role of past experience with food types in the responses of individuals of three species of crayfish (Orconectes virilis, $O$. rusticus, and Cambarus robustus) to food odor cues. During the course of these experiments, the response pattems of crayfish suggested investigation of the possible role of microbial degradation of food proteins in the generation of food cues.

\section{METHODS AND MATERIALS}

The experiments were done in the laboratory in Ann Arbor, Michigan, and at the University of Michigan Biological Station in Pellston, Michigan. The individuals of Orconectes virilis (Hagen, 1870) were collected from either the Maple River in northern Michigan or Fleming Creek near Ann Arbor, Michigan. The individuals of Cambarus robustus (Girard, 1852) utilized were collected from Paint Creek near Ypsilanti, Michigan. None of these waters supported any zebra mussels Dreissena polymorpha (Pallas, 1773) at the time the crayfish were collected; thus the crayfish were naive with regards to that species. The Orconectes rusticus (Girard, 1852) used were obtained from a commercial supplier in Wisconsin and had been maintained in the laboratory for two months prior to the start of treatments for these experiments. Zebra mussels were collected from Lake Erie, Monroe Beach, in Monroe, Michigan. The native gastropods Stegnicola elodes (Say, 1821) and Aplexa elongata (Say, 1821) were utilized in experiments with $O$. rusticus and were collected from a drainage ditch near the Huron River in Ann Arbor.

All the crayfish used in these experiments were adults and were maintained and fed in 30-gal aquaria with constant aeration and filtration. Crayfish were fed daily with either canned tuna (the control $O$. rusticus), commercial shrimp pellets (controls for $O$. virilis and $C$. robustus), or freshly crushed mollusks. 
After being fed a prey type for the designated time period (see below), crayfish were placed individually in visually isolated 10 -gal aquaria with a clay burrow and 12.5 liters of water, which was continually aerated. After a 24 -hr adjustment period, test solutions were introduced to individual crayfish and each was observed for $5 \mathrm{~min}$ during the late moming or early afternoon. The latency to first feeding responses and the duration of feeding responses were recorded. Feeding was recognized either by the combination of locomotion, elevated body and raised chelae (while this can be the initial response to some other stimuli, it is the initial response shown to the introduction of food), or by elevated body and rapid scraping movements of the chelated ambulatory legs (Ameyaw-Akumfi, 1977). Ten replicates were run for each treatment.

Statistical analyses were by one-way ANOVA with individual contrasts. All differences reported were associated with $P<0.05$ and most were associated with $P<0.01$. Differences in latency and duration among treatments or tests were (almost) always similar, i.e., both were significantly different or both were not significant; thus only duration measures are reported in most situations.

Experience Tests. To test the role of past experience with a food type, individuals were fed for two weeks with freshly crushed mollusks or not fed mollusks. Following this, test solutions were prepared by placing $5 \mathrm{~g}$ of prey flesh in $200 \mathrm{ml}$ of distilled water, mixing, and filtering through Fisher P8 coarse filter paper. Twenty milliliters of solution was introduced via syringe into a comer of an individual crayfish's aquarium and data recording started.

There are several mechanisms through which past experience can affect behavior. Associative learning involves the formation of an association or linkage between two features, while sensory sensitization involves changes in how an animal utilizes a single sensory input (Dickinson, 1980). To rule out sensitization as the mechanism for differences in feeding responses with experience, individuals of $O$. virilis that had no experience feeding upon zebra mussels were exposed daily for two weeks to a freshly prepared filtrate of zebra mussel but fed shrimp pellets at different times of the day (to eliminate the formation of an association between zebra mussel smell and food). These animals, which experienced only odor of zebra mussels, were tested with a standard zebra mussel filtrate.

There are two possible mechanisms of the formation of an association by crayfish. This is because individuals of $O$. virilis respond to some prey solutions with a combination of feeding and alarm responses (Hazlett, 1994). Thus, experienced animals could be learning either to associate prey smell with prey taste or could be learning to not respond to alarm substances from the prey and just respond to the food odors. Freeze-thawing apparently destroys the alarm substance (Hazlett, 1994), thus a freeze-thawed filtrate should contain only potential food cues, not alarm chemicals. Animals experienced with odor only were 
tested with the freeze-thawed filtrate to distinguish between the two types of associative learning.

The temporal pattern of learning was studied in two ways. Individuals of $O$. virilis that had no experience feeding on zebra mussels were given one feeding experience (one crushed zebra mussel per crayfish overnight) and then placed in an observation aquarium and tested with zebra mussel filtrate. Extinction of responses was tested with crayfish that had two weeks of experience feeding on freshly crushed zebra mussels but then were given no further experience with that species and fed commercial shrimp pellets for 20 days. These individuals were tested with the standard filtrate and then tested a second time 20 days later ( 40 days after their last experience feeding on mussels).

Microbial Degradation. During a set of pilot experiments, a test solution was stored in a refrigerator for several hours prior to use. The solution produced no feeding responses with experienced crayfish during the standard 5-min period, but about $20 \mathrm{~min}$ later full feeding responses were shown by the crayfish. This suggested that cooling had some effect upon the test solutions, and one possibility was that microbial degradation had been slowed down. To test this possibility, two experiments were done. Crayfish experienced with a food type were used in both experiments. Individuals of $O$. virilis were given either standard filtrates of freshly crushed zebra mussels that had been at room temperature for $1 \mathrm{hr}$ or filtrates that had been exposed for $1 \mathrm{hr}$ to short wavelength UV radiation $(254 \mathrm{~nm})$ in shallow dishes. To control for the possibility that the radiation altered chemical cues (in addition to killing microorganisms), a UV-treated solution had $1 \mathrm{mg}$ of trypsin (Nasco trypsin) added per $100 \mathrm{ml}$ just prior to introduction of the solutions to the crayfish. This tested for the presence of suitable substrate in the UV-treated filtrate.

In the case of $O$. rusticus, filtrates of freshly crushed gastropods were prepared and then microfiltered through an Acrodisc filter (Gelman Sciences), which has a pore size of $0.2 \mu \mathrm{m}$. Bacteria cannot pass through this filter. This microfiltrate was introduced to experienced crayfish. To test for the presence of appropriate substrate in the microfiltrate, solutions were treated with trypsin and then introduced to crayfish. A control of trypsin in distilled water (with no substrate present) was also introduced to experienced crayfish.

\section{RESULTS}

When crushed mollusks were introduced to naive crayfish, no feeding responses were seen until contact was made with the mollusk flesh by setae on the crayfish's walking legs or maxillipeds. This was true for all three species of crayfish and both categories of mollusks. Once physical contact was made, the crayfish fed vigorously on crushed mollusks. However, even experienced 
individuals of $O$. virilis and Cambarus robustus did not feed upon larger (20to 25 -mm-long) zebra mussels living with them. Very large individuals of $C$. robustus (carapace length 55-60 $\mathrm{mm}$ ) were often observed scraping around the valves of mussels with their mouthparts but did not crush or break the valves during many weeks of postexperimental cohabitation.

Individuals of $O$. virilis that had experience with zebra mussels responded to zebra mussel odors with feeding responses, while crayfish without experience did not (Table 1, experiment 1 vs. 2). This experience involved associative learning rather than some form of sensitization because individual $O$. virilis that were exposed daily for two weeks to just the smell (but not the taste) of crushed zebra mussels behaved similarly to inexperienced crayfish (experiments 2 and 3 ). Because $O$. virilis shows an alarm response to some freshly crushed prey species (Hazlett, 1994), the role of experience could be to overrule a possible alarm response rather than to associate food odors (detected by the antennules)

\section{Table 1. Responses of Crayfish Following Presentation of Test Solutions ${ }^{a}$}

\begin{tabular}{|c|c|c|c|}
\hline \multirow{2}{*}{$\begin{array}{l}\begin{array}{c}\text { Experiment number and } \\
\text { animal's experience }\end{array} \\
\text { Trconectes virilis }\end{array}$} & \multirow[t]{2}{*}{ Test solution } & \multicolumn{2}{|c|}{$\begin{array}{l}\text { Feeding response } \\
\text { duration, } \\
\sec ( \pm S E)\end{array}$} \\
\hline & & & \\
\hline 1 Fed $\mathrm{ZM}$ & Standard ZM & 133 & (35) \\
\hline 2 No ZM experience & Standard ZM & 9 & (8) \\
\hline 3 ZM odor experience & Standard ZM & 11 & (11) \\
\hline $4 \mathrm{ZM}$ odor experience & Freeze-thaw $\mathrm{ZM}$ & 27 & (11) \\
\hline 524 Hours $Z M$ exp. & Standard ZM & 43 & (15) \\
\hline 6 Fed $Z M, 20$ days $w / 0$ & Standard ZM & 145 & (34) \\
\hline 7 Fed ZM, 40 days $w / 0$ & Standard ZM & 26 & (9) \\
\hline 8 Fed ZM & Standard ZM & 164 & (24) \\
\hline 9 Fed ZM & $\mathrm{ZM}$ solution UV treated & 79 & (37) \\
\hline 10 Fed $Z M$ & ZM solution UV treated + trypsin & 161 & (31) \\
\hline \multicolumn{4}{|l|}{ Mrconectes rusticus } \\
\hline 11 Fed snails & Standard snail & 131 & (31) \\
\hline 12 No snail experience & Standard snail & 37 & (15) \\
\hline 13 Fed snails & Tuna & 212 & (8) \\
\hline 14 Fed tuna & Tuna & 241 & (18) \\
\hline 15 Fed snails & Snail solution microfiltered & 37 & (11) \\
\hline 16 Fed snails & Snail solution microfiltered + trypsin & 169 & (39) \\
\hline 17 Fed snails & Trypsin alone & 21 & (15) \\
\hline \multicolumn{4}{|l|}{ Jambarus robustus } \\
\hline 18 Fed ZM & Standard ZM & 150 & (35) \\
\hline 19 No $\mathrm{ZM}$ experience & Standard ZM & 69 & (20) \\
\hline
\end{tabular}

Ten crayfish per experiment. $\mathrm{ZM}=$ zebra mussel. Dreissena polymorpha. 
and food tastes (detected by contact chemoreceptors on other appendages). To test this idea, freeze-thawed preparations of zebra mussel flesh were introduced, but the responses of crayfish that had been exposed only to zebra mussel odor were the same for the freeze-thawed solution and the standard solution (Table 1 , experiments 3 and 4 ). Thus, the mechanism of learning appears to be the formation of an association between food odors and food taste.

Individuals of $O$. virilis given just one feeding with crushed zebra mussels did not show a feeding response to odor when tested $24 \mathrm{hr}$ later (experiment 5), suggesting that repeated experiences are required for establishment of an association. Experienced individuals that had not been fed zebra mussels for three weeks still showed a full-strength response to food odors (experiment 6), but by six weeks without experience, their average response level had declined to control levels (experiment 7 ).

Individuals of Orconectes rusticus that had been fed a mixture of crushed gastropods showed a significantly stronger feeding response to crushed gastropods than those that had no experience with gastropods (Table 1, experiment 11 vs. 12). Individuals of Cambarus robustus also showed a significantly stronger feeding response to zebra mussel odor if they had prior experience with zebra mussel flesh in the previous 14 days (Table 1 , experiment 18 vs. 19). Thus, experience plays a significant role both for different crayfish species and for different food types.

Individual $O$. virilis that were experienced with feeding on zebra mussels were tested with solutions of crushed zebra mussels treated with UV radiation to kill all microorganisms. Crayfish showed a nearly significant decrease in feeding duration $(P=0.064)$ and a significant increase in latency $(P=0.017)$ (experiment 8 vs. 9). Addition of trypsin to the UV-treated solutions fully restored the stimulating power of the solutions (experiment 10), indicating that the chemical substrate for odor production was not eliminated by the UV treatment.

In the case of $O$. rusticus, crushed snail solutions were coarse filtered and then microfiltered to remove all microorganisms. These solutions were introduced to individual $O$. rusticus experienced with feeding on those snails, but the crayfish showed no feeding response (experiment 11 vs. 15). When such microfiltered solutions were treated with the enzyme trypsin, a full feeding response was shown (experiment 16), indicating that appropriate substrate was present in the microfiltrate. No feeding was shown when the trypsin control was introduced (experiment 17).

\section{DISCUSSION}

These results indicate that crayfish do not respond to food odors from animal protein sources unless they have had experience with that protein source. Without an association between taste and odor gained while feeding on damaged 
prey, odors apparently do not signal food to adult animals. Presumably under field conditions, contact with damaged prey could occur with some regularity. Although it appeared to take more than one feeding bout to form the association between taste and odor, once formed, this association persisted for at least three weeks. Although the same individuals were tested twice (at 20 and 40 days after the last experience with feeding on mussels), the results clearly indicate a decline in responsiveness somewhere between three and six weeks.

Perhaps the more important result from these experiments is that with the elimination of enzymatic activity of microorganisms (probably bacteria), which degrades protein sources, food odors are not produced in sufficient quantities to stimulate feeding by experienced animals. The small molecules that constitute food signals (amino acids and small polypeptides) for many aquatic organisms apparently do not appear in the water immediately after damage without degradation by microbe-sized particles (the microfiltration experiment). The strong responses shown to a food source such as canned tuna may relate to the degradation of proteins that has occurred during the canning process. The process of freezing and thawing also releases many autochthonous enzymes that can degrade proteins (Rittschof, 1980) and release the small molecules used as cues for the presence of larger, less volatile molecules. Rittschof (1993) reviews a number of cases where enzymatic activity is necessary for the generation of odor cues.

Thus, with experienced crayfish, elicitation of feeding appears to be microbe-dependent. I predict that we will find that most other organisms are dependent upon microbial degradation for food odor cues in nature.

Acknowledgments-The Cambarus robustus used in this study were collected in part by Rand Zaremba and the Dreissena polynorpha by Lou Ann Reich. The gastropods were identified by Jack Burch. Discussions of procedures with Eric Mann and Charles Yocum were very helpful. The manuscript was improved by comments from Catherine Bach and Robert Thacker.

\section{REFERENCES}

AMEYAW-AKUMFi, C. 1977. Feeding chemoreceptor sites in the crayfish Procambarus clarkii (Girard). Crustaceana 33:259-264.

Chamgers, P.A., Hanson, J.M., Burke, J.M., and Prepas, E.E. 1990. The impact of the crayfish Orconectes virilis on aquatic macrophytes. Freshwater Biol. 24:81-91.

Connaughton, V.P., and EPIfanio, C.E. 1993. Infuence of previous experience on the feeding habits of larval weakfish Cynoscion regalis. Mar. Ecol. Prog. Ser. 101:237-241.

CROLL, R.P., and CHASE, R. 1980. Plasticity of olfactory orientation to foods in the snail Achatina fulica. J. Comp. Physiol. 136A:267-277.

DERBY, C.D., and ATEMA, J. 1981. Selective improvement in responses to prey odor by the lobster, Homarus americanus, following feeding experience. J. Chem. Ecol. 7:1073-1080.

Dickinson, A. 1980 . Contemporary Animal Learning Theory. Cambridge University Press, New York. $177 \mathrm{pp}$. 
FLINT, R.W., and GoldMAN, C.R. 1975. The effects of a benthic grazer on the primary productivity of the littoral zone of Lake Tahoe. Limnol. Oceanogr. 20:935-944.

HAZLETT, B.A. 1994. Alarm responses in the crayfish Orconectes virilis and Orconectes propinquus. J. Chem. Ecol. 20:1525-1535.

HoBes, H.H., IIl. 1993. Trophic relationships of North American freshwater crayfishes and shrimps. Contrib. Biol. Geol. Milwaukee Mus. 85:1-110.

IKESHOII, T. 1984. S-Propenylcysteine sulfoxide in exudates of onion roots and its possible decompartmentalization in root cells by bacteria into attractant of the onion maggot Hylemya antiqua (Diptera: Anthomyidae). Appl. Entomol. Zool. 19:159-169.

LovE, J., And SAvino, J.F. 1993. Crayfish (Orconectes virilis) predation on zebra mussels (Dreissena polymorpha). J. Freshwater Ecol. 8:253-259.

LudYanskiY, M.L., MCDONALD, D., and MACNEnLl, D. 1993. Impact of the zebra mussel, a bivalve invader. Bioscience 43:533-544.

Momot, W.T., Gowing, H., and Jones, P.D. 1978. The dynamics of crayfish and their role in ecosystems. Am. Midl. Nar. 99:10-35.

RutTschoF, D. 1980. Enzymatic production of small molecules attracting hermit crabs to simulated gastropod predation sites. J. Chem. Ecol. 6:665-675.

RITTSCHOF, D. 1993. Body odors and neutral-basic peptide mimics: A review of responses by marine organisms. Am. Zool. 33:487-493.

TIERNEY, A.J., and ATEMA, J. 1988. Behavioral responses of crayfish (Orconectes virilis and Orconectes rusticus) to chemical feeding stimulants. J. Chem. Ecol. 14:123-133.

VISSEN, J.H. 1986. Host odor perception in phytophagous insects. Annu. Rev. Entomol. 31:121144.

Waldbauer, G.P., and Friedman, S. 1991. Self-selection of optimal diets by insects. Annu. Rev. Entomol. 36:43-63.

Wood, L. 1968. Physiological and ecological aspects of prey selection by the marine gastropod Urosalpinx cinerea (Prosobranchia: Muricidae). Malacolgia 6:267-320. 